\title{
A APOSENTADORIA RURAL E A CONSTRUÇÃO DA AUTONOMIA FEMININA NO TERRITÓRIO QUILOMBOLA DE PORTO ALEGRE, PARÁ ${ }^{1}$
}

\author{
Marcelo Rodrigues Lopes ${ }^{2}$ \\ https://orcid.org/0000-0002-4917-0575 \\ Monique Medeiros ${ }^{3}$ \\ https://orcid.org/0000-0001-8789-0621 \\ Andréia Tecchio ${ }^{4}$ \\ https://orcid.org/0000-0003-0283-9996
}

\section{RESUMO}

Este trabalho tem por objetivo compreender a importância da previdência social rural para a autonomia de mulheres quilombolas e o papel desta política no desenvolvimento rural da Comunidade Quilombola de Porto Alegre, Cametá/PA. A construção de dados, ancorada na abordagem qualitativa, foi realizada por meio de pesquisas bibliográficas, da observação participante e da realização de quatro entrevistas abertas envolvendo mulheres quilombolas aposentadas da Comunidade. As entrevistas foram guiadas pelo método de história de vida e a análise do conteúdo baseou-se na abordagem das capabilities, de Amartya Sen. A pesquisa indica que a aposentadoria rural garante diferentes graus de autonomização para a vida dessas mulheres, lhes ofertando novas capabilities, que modificam de forma positiva as subjetividades das agricultoras. A operacionalização dessa política pública pelas mãos das mulheres rurais garante às famílias quilombolas de Porto Alegre a superação da extrema pobreza, por meio da catalisação de estratégias de reprodução socioeconômica, o que, por sua vez, irradia consequências positivas ao desenvolvimento da referida Comunidade.

Palavras-chave: Política Pública, Capabilities, Previdência Social Rural, Mulheres Quilombolas.

\section{RURAL RETIREMENT AND THE CONSTRUCTION OF FEMALE AUTONOMY IN THE QUILOMBOLA TERRITORY OF PORTO ALEGRE, PARÁ}

\begin{abstract}
This work aims to understand the importance of rural social security for the autonomy of quilombola women and the role of this policy in the rural development of the Quilombola Territory of Porto Alegre, Cametá/PA. The construction of data, anchored in the qualitative approach, was carried out through bibliographic research, participant observation and four open interviews involving retired quilombola women from the Community. The interviews were guided by the life history method and the content analysis was based on the capabilities approach, by Amartya Sen. The research indicates that rural retirement guarantees different degrees of autonomy for the lives of these women, offering them new capabilities, that positively modify the subjectivities of female farmers. The operationalization of this public policy by the hands of rural women guarantees the quilombola families of Porto Alegre the overcoming of extreme poverty, through the catalysis of socioeconomic

\footnotetext{
1 Os autores agradecem ao CNPq pelo apoio financeiro concedido à realização de pesquisa de campo, por meio do projeto "Tecnologia e Inovação Social na Amazônia Oriental: articulando produção e sustentabilidade na consolidação da agricultura familiar quilombola", aprovado na chamada CNPq/MCTIC/MDS no 36/2018 - Tecnologia Social. E à PróReitoria de Pesquisa e Pós Graduação da UFPA, a qual financiou uma bolsa de iniciação científica vinculada ao projeto aprovado na chamada CNPq de 2020.

2 Graduando em Agronomia no Campus Universitário do Tocantins, CUNTINS/UFPA. E-mail: marceloagro016@gmail.com.

3 Doutora pelo Programa de Pós Graduação em Agroecossistemas (PGA/UFSC). Professora no Instituto Amazônico de Agriculturas Familiares - INEAF/UFPA. E-mail: mmedeiros@ymail.com.

4 Pós-Doutoranda no Programa de Pós-Graduação em Agroecossistemas (PGA/UFSC). E-mail: deiatecchio@yahoo.com.br.
} 
reproduction strategies, which, in turn, radiates positive consequences for the development of the Quilombola Territory of Porto Alegre.

Keywords: Public Policy, Capabilities, Social Security Rural, Quilombola Women.

\title{
JUBILACIÓN RURAL Y CONSTRUCCIÓN DE LA AUTONOMÍA FEMENINA EN EL TERRITORIO QUILOMBOLA DE PORTO ALEGRE, PARÁ
}

\begin{abstract}
RESUMEN
Este trabajo tiene como objetivo comprender la importancia de la seguridad social rural para la autonomía de las mujeres quilombolas y el papel de esta política en el desarrollo rural del Territorio Quilombola de Porto Alegre, Cametá/PA. La construcción de datos, anclada en el enfoque cualitativo, se llevó a cabo a través de la investigación bibliográfica, la observación participante y cuatro entrevistas abiertas a mujeres quilombolas jubiladas de la Comunidad. Las entrevistas fueron guiadas por el método de historias de vida y el análisis de contenido se basó en el enfoque de capacidades de Amartya Sen. La investigación indica que la jubilación rural garantiza diferentes grados de empoderamiento para la vida de estas mujeres, ofreciéndoles nuevas capacidades, que modifican positivamente las subjetividades de las agricultoras. La operacionalización de esta política pública por parte de las mujeres rurales garantiza a las familias quilombolas de Porto Alegre la superación de la pobreza extrema, mediante la catálisis de estrategias de reproducción socioeconómica, que, a su vez, irradia consecuencias positivas para el desarrollo del Territorio Quilombola de Porto Alegre.

Palabras-clave: Política Pública, Capabilities, Seguridad Social Rural, Mujeres Quilombolas.
\end{abstract}

\section{INTRODUÇÃO}

O sistema previdenciário para agricultores familiares foi ampliado com a Constituição Federal de 1988 e aplicado de fato a partir de 1992. Considerado o "vagão tardio do direito social trabalhista brasileiro" (Delgado, 2015, p. 429), o princípio desse sistema é a distribuição de renda que garante a manutenção de famílias aposentadas, acima da linha da pobreza, em domicílios rurais de todas as regiões brasileiras (Delgado; Cardoso Jr., 1999).

Antes da Constituição Federal de 1988, existia o chamado Fundo de Assistência e Previdência do Trabalhador Rural (Funrural), criado em 1971, que garantia o direito de aposentadoria especial somente ao chefe do estabelecimento, e no valor de meio salário mínimo (Delgado, 2015). As mudanças normativas asseguradas pela Constituição Federal de 1988 dizem respeito à equiparação das condições de acesso para homens e mulheres, ou seja, as mulheres passaram a ter acesso à aposentadoria independentemente de o cônjuge já ser beneficiário ou não; e houve a redução do limite de idade para essa aposentadoria, de 65 para 60 anos se homem, e de 60 para 55 anos se mulher (Delgado, Cardoso Jr, 1999). Além disso, segundo esses autores, o piso de benefícios para aposentadorias e pensões, que era de meio salário mínimo, passou a ser de um.

Ainda são incipientes os estudos sobre a influência da aposentadoria rural para famílias quilombolas, especialmente para a vida das mulheres quilombolas da Amazônia ${ }^{5}$. Algumas pesquisas

\footnotetext{
5 Neste artigo, o contexto referencial em estudo para embasamento das análises é o do território da Amazônia Legal.
} 
realizadas por Fucks e Ferreira (2013) e Pedroso Júnior et. al. (2008), respectivamente nos estados do Rio Grande do Sul e de São Paulo, indicam que, para as unidades produtivas dos territórios quilombolas, a aposentadoria rural possibilita a aquisição mensal e manutenção de recursos domésticos, especialmente da alimentação, para si e seus dependentes. Já Jorge e Brandão (2012), ao estudarem as dificuldades do acesso à previdência rural entre mulheres quilombolas da comunidade do Agreste, no município de São João da Ponte, em Minas Gerais, identificaram que a ausência de reconhecimento do trabalho feminino e as exigências comprobatórias para o acesso à previdência demonstram a fragilidade da universalização desta política, pois promove a exclusão de mulheres.

Entre as questões sobre a influência da aposentadoria na vida de mulheres quilombolas amazônicas que carecem elucidações, foram elencadas as seguintes: como se dá a operacionalização dessa política pública nos núcleos familiares de comunidades mais afastadas de grandes centros? O acesso à aposentadoria promove a autonomia para as mulheres quilombolas amazônicas? Qual é a influência desta política na reprodução socioeconômica das unidades produtivas? Buscando respostas para tais questionamentos, o objetivo deste artigo consiste em compreender a importância da previdência social rural para a autonomia de mulheres quilombolas e o papel desta política no desenvolvimento rural.

Para o alcance desse objetivo, elegeu-se como lócus de pesquisa a Comunidade Quilombola de Porto Alegre, Cametá, Pará, que integra o Território do Baixo Tocantins (Figura 1). Este Território abrange uma área de 36.024,20 km² e possui 11 municípios: Abaetetuba, Acará, Baião, Barcarena, Cametá, Igarapé-Miri, Limoeiro do Ajuru, Mocajuba, Moju, Oeiras do Pará e Tailândia. Segundo dados do Censo do IBGE (2010), no referido Território, 390.579 (52,79\%) pessoas residem no meio rural, e 349.302 (47,21\%) são habitantes no meio urbano.

Figura 1 - Localização do Território do Baixo Tocantins.

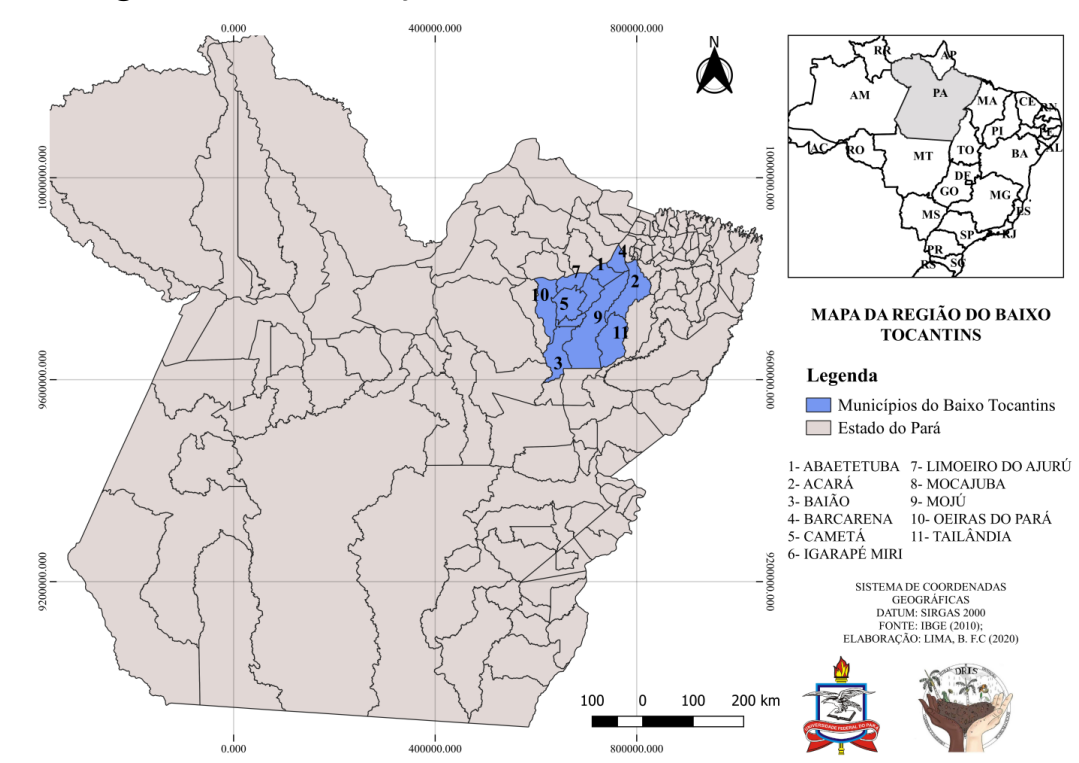

Fonte: IBGE (2010). Elaborado por Lima (2020). 
A Comunidade Quilombola Porto Alegre, onde foi realizada a pesquisa de campo, situa-se a $45 \mathrm{~km}$ do centro urbano de Cametá, próxima da BR 422, às margens do Igarapé Anauerá, cujo acesso se dá por via terrestre. A comunidade possui uma área de 2.858,7 hectares (Iterpa, 2020), na qual residem 90 famílias, distribuídas em 80 residências, cuja população total é de aproximadamente 400 habitantes. Um dos fatos importantes na história da construção dessa Comunidade foi a formação da Associação dos Remanescentes de Quilombos de Porto Alegre (ARQUIPA), em 2006, com apoio importante da MALUNGU, uma organização sem fins lucrativos, e que representa as comunidades quilombolas do Pará. Este apoio foi essencial para que Porto Alegre obtivesse o Título de Reconhecimento de Domínio Coletivo junto ao Instituto de Terras do Pará (ITERPA), em novembro de 2007.

A escolha desta comunidade para a realização da etapa de campo se deve principalmente à sua relativa proximidade geográfica aos Campus da Universidade Federal do Pará (UFPA), da Universidade do Estado do Pará (UEPA) e do Instituto Federal do Pará (IFPA). Essa proximidade é um dos fatores facilitadores para que distintos jovens quilombolas de Porto Alegre estejam cursando o ensino superior nessas instituições e, consequentemente, trazendo as problemáticas de sua Comunidade como pauta de discussão nesses espaços de educação formal. Isso desencadeia o vínculo desses jovens a projetos de extensão e de pesquisa, como por exemplo, no projeto que viabilizou a operacionalização da investigação atrelada a este artigo e que conta com dois jovens dessa comunidade como investigadores.

As ferramentas metodológicas adotadas nesta pesquisa consistiram em levantamento bibliográfico, observação participante e realização de entrevistas abertas. A pesquisa de campo aconteceu entre janeiro e fevereiro de 2020, sendo que foram feitas quatro entrevistas, cada uma possuindo duração média de 50 minutos. A construção destes dados foi embasada no método de história de vida, que, segundo Santos e Santos (2008), permite obter informações na essência subjetiva da vida de uma pessoa, e, caso se queira saber a experiência e perspectiva de um indivíduo, não há melhor caminho do que obter estas informações através da própria voz da pessoa.

Para esta pesquisa, o número de interlocutoras foi determinado pela técnica Snowball, ou Bola de Neve (Vinuto, 2014), por meio da qual a indicação dos moradores da comunidade foi considerada e, por sua vez, a própria indicação das interlocutoras auxiliou nessa seleção. A partir das indicações recebidas, a ponderação para a escolha do grupo selecionado baseou-se em fatores como: ser do sexo feminino; possuir residência fixa na comunidade; receber aposentadoria rural; ter disponibilidade de tempo para a realização das entrevistas; e assentir compartilhar sua rotina diária, parte essencial para a efetividade da observação participante. Se faz necessário frisar que a identidade das entrevistadas foi preservada e, portanto, nos trechos de entrevistas expostos no artigo, as interlocutoras serão 
identificadas por meio de numeração arábica, a exemplo: entrevistada 1, entrevistada 2 , entrevistada 3 e assim por diante.

Previamente às entrevistas, os objetivos e as proposições a serem investigadas eram apresentados às interlocutoras e, somente após a anuência destas, iniciava-se a conversa. As entrevistas foram gravadas, transcritas e, utilizando os pressupostos da análise de conteúdo (Bardin, 1979), lidas, até que as ideias pudessem ser sistematizadas e delas extraídas as "unidades de significação" da investigação. As unidades de significação identificadas e discutidas mais a frente, recaem especialmente sobre a percepção de modificações das singularidades que o acesso à renda fixa promoveu na vida das aposentadas, com foco na percepção da construção da sua autonomia pessoal; e o entendimento do processo de operacionalização mensal da renda da aposentadoria rural pelas mulheres.

A observação participante consistiu na permanência dos pesquisadores na comunidade, estes frequentemente se deslocando em trio e realizando idas a campo mensais, com estada de cinco a sete dias in loco. Nestes momentos, além de terem realizado as entrevistas, os pesquisadores vivenciaram o cotidiano das mulheres, por meio da participação em atividades agrícolas e conversas com integrantes das famílias e com lideranças da comunidade. Vale destacar que essas conversas, geralmente, decorriam nos quintais das residências.

Com intuito de aprofundar as problemáticas aqui apresentadas, o artigo está dividido em três seções, além desta introdução e das considerações finais. A primeira evidencia o arcabouço teórico utilizado neste artigo, dando maior ênfase à abordagem das capabilities, vinculando-a à aposentadoria rural. A segunda realiza uma explanação sobre a agricultura quilombola amazônica e a invisibilidade do trabalho feminino no campo. A terceira discute a relevância da aposentadoria rural na construção da autonomia feminina e das capabilities entre as mulheres, além da compreensão de como ocorre sua operacionalização na comunidade de Porto Alegre. Nas considerações finais, é reforçada a reflexão acerca de como a aposentadoria é essencial para a continuidade das atividades agrícolas quilombolas e como este provento protagoniza a autonomia das mulheres entrevistadas.

\section{CAPABILITIES COMO RESULTANTE E INSTRUMENTO DE PROCESSO NA OPERACIONALIZAÇÃO DA APOSENTADORIA RURAL}

A abordagem sobre desenvolvimento adotada neste artigo foi elaborada por Sen (2000). Este autor relacionou a renda com realizações individuais, pois permite aos indivíduos efetuarem aquilo que gostam, todavia, questionando o seu entendimento como um fim em si mesmo. Sen (2000) menciona que o desenvolvimento pode ser visto como a expansão de liberdades (capabilities). Ainda segundo o economista social, o desenvolvimento requer que se retirem as principais fontes de privação da liberdade dos sujeitos, como a "[...] pobreza, tirania, carência de oportunidades 
econômicas e destituição social sistemática, negligência dos serviços públicos e intolerância ou interferência excessiva de Estados repressivos" (Sen, 2000, p. 16).

Sen (2000) reforça a ideia de que reduzir a pobreza de renda significa, sobretudo, minimizar o grande hiato que separa homens e mulheres. As mulheres destinam parte do seu tempo às tarefas do lar, e que por não serem consideradas atividades produtivas, não são contabilizadas nas contribuições para o sustento da família. Por outro lado, quando elas trabalham fora do ambiente doméstico com remuneração, a renda lhes confere visibilidade dentro do lar (Sen, 2000).

Com foco na vida humana, utiliza-se neste artigo as bases conceituais de análise de políticas públicas por meio da abordagem das capabilities, pois estas enfatizam as oportunidades reais da vida (Sen, 2011). Esta abordagem também considera e avalia os arranjos sociais, a concepção de políticas públicas e de propostas de mudança social, dedicando-se aos aspectos relativos ao desenvolvimento e à justiça (Robeyns, 2011).

O sistema previdenciário rural teve desempenho eficaz no Brasil, principalmente em relação ao avanço significativo do seguro social aos vários grupos da agricultura familiar do meio rural brasileiro; melhorou expressivamente o nível e a distribuição da renda familiar rural, promovendo a redução da pobreza, e, embora não tenha sido planejado, contribuiu nas melhorias produtivas na agricultura familiar (Delgado, 2015).

De acordo com o inciso VII do artigo $11^{\circ}$ da Lei ${ }^{\circ}$ 8.213/91, são beneficiários dessa política pública:

\footnotetext{
o produtor, o parceiro, o meeiro e o arrendatário rurais, o garimpeiro, o pescador artesanal e o assemelhado, que exerçam suas atividades, individualmente ou em regime de economia familiar, ainda que com o auxílio eventual de terceiros, bem como seus respectivos cônjuges ou companheiros e filhos maiores de dezesseis anos ou a eles equiparados, desde que trabalhem, comprovadamente, com o grupo familiar respectivo.
}

Segundo dados de INSS (2019a), atualmente, existem no Brasil mais de nove milhões e meio de benefícios previdenciários destinados à categoria de agricultores familiares, representando cerca de $27 \%$ do total de benefícios previdenciários. Os dados também evidenciam que o valor médio atual das previdências rurais se equipara ao valor do salário mínimo. Diversos estudos, como o de Delgado (2015) e Valadares e Galiza (2016), têm demonstrado que este valor impacta diretamente na redução da pobreza no meio rural brasileiro, à medida que facilita a reprodução econômica de uma parcela da população que, em muitos casos, não teria condições de sobreviver dignamente sem a proteção proporcionada pela política social.

Na região Norte do Brasil, a aposentadoria rural representa mais da metade dos benefícios previdenciários totais (INSS, 2019a), denotando a importância das políticas públicas sociais para o meio rural. Embasado na estimativa populacional do IBGE (2010), que indica que 32\% da população 
paraense está nas áreas rurais, e comparando este percentual com o dos benefícios previdenciários, conclui-se que, no estado, o espaço rural é composto por uma parcela considerável de idosos. A esse respeito, Wanderley (2001) destaca que, no passado, as pessoas que deixavam as atividades agrícolas, abandonavam também o meio rural. Porém, com base nos dados acerca do estado do Pará, percebese a transformação dessa realidade, o que pode estar diretamente imbricado com a mudança de percepção do rural pela sociedade. Antes, exclusivamente visto como espaço de trabalho penoso e mal remunerado, hoje vem sendo concebido, para além de um espaço produtivo de trabalho árduo, como sendo mais bem reconhecido e como um atrativo para descanso e lazer, no qual grande número de aposentados permanece após o período de atividade produtiva.

O Quadro 1 apresenta os indicadores dos benefícios previdenciários do estado do Pará, do município de Cametá e da Comunidade de Porto Alegre, a partir da qual serão tecidos comentários acerca da análise da previdência rural no município. Os dados apresentados no quadro abaixo, referentes à Comunidade de Porto Alegre, foram alcançados a partir de uma base de informações que os próprios comunitários construíram, visto que, nos sites e documentos oficiais do Governo Federal, há apenas os dados gerais do município de Cametá e do estado do Pará.

Quadro 1. Quantidade total, quantidade de benefícios rurais, percentual dos benefícios rurais sobre a população e valor médio dos benefícios previdenciários no estado do Pará, no município de Cametá e na Comunidade de Porto Alegre, em dezembro/2019.

\begin{tabular}{|l|r|r|r|r|}
\hline UF/município & $\begin{array}{l}\text { Quantidade total } \\
\text { de benefícios } \\
\text { previdenciários }\end{array}$ & $\begin{array}{l}\text { Quantidade de } \\
\text { benefícios rurais }\end{array}$ & $\begin{array}{l}\text { \% dos benefícios } \\
\text { rurais em relação } \\
\text { ao total de } \\
\text { benefícios } \\
\text { previdenciários }\end{array}$ & $\begin{array}{l}\text { Valor médio dos } \\
\text { benefícios } \\
\text { previdenciários } \\
\text { rurais (R\$) }\end{array}$ \\
\hline Pará & 689.410 & 436.481 & 63,3 & 852,31 \\
Cametá & 16.392 & 15.270 & 93,1 & 830,96 \\
Porto Alegre & 33 & 33 & 100 & - \\
\hline
\end{tabular}

Fonte: INSS (2019b). Elaborado pelos autores.

O município de Cametá é essencialmente rural, apresentando cerca de $60 \%$ da sua população nos interiores de ilhas e comunidades tradicionais (IBGE, 2010). Enfatiza-se então, à luz dos dados mais recentes do INSS (2019b), a relevância da política pública nesse contexto. O Quadro 1 indica que o município de Cametá possui cerca de 3,5\% do total dos benefícios previdenciários rurais do estado do Pará, e que, para os aposentados rurais deste município, o valor médio da sua aposentadoria é mais baixo quando comparado com a média estadual. Ao partir do contexto da Comunidade de Porto Alegre, pode-se depreender que uma possível explicação para essa diferença de valores médios no benefício ocorra devido à realização de empréstimos consignados pelos aposentados, que compromete uma parcela dos proventos mensais destes idosos. Ainda analisando os dados acima, compreende-se que a previdência social rural representa mais de $90 \%$ dos benefícios previdenciários 
totais do município de Cametá, totalizando mais de quinze mil idosos de Cametá que são beneficiados por esta política pública.

$\mathrm{Na}$ Comunidade de Porto Alegre, observa-se que há 33 pessoas assistidas pela previdência rural, sendo que, destes, 20 são mulheres aposentadas, logo, aportados pelo quantitativo total de beneficiários, é possível verificar que mais de $8 \%$ da população deste Território se beneficia desta política pública, uma representação significativa e acima da média estadual. Portanto, diante das informações do Quadro 1, infere-se que a previdência social rural assume um papel social de destaque na distribuição de renda, influenciando positivamente na dinâmica econômica de pequenos municípios e dos territórios tradicionais, como é o caso da população rural residente em Cametá e na comunidade de Porto Alegre.

\section{AGRICULTURA FAMILIAR AMAZÔNICA: OLHARES ATENTOS ÀS PECULIARIDADES DE PRÁTICAS NA COMUNIDADE PORTO ALEGRE}

As atividades econômicas rurais da região amazônica estão baseadas em unidades de produção familiares, assentadas principalmente na mão de obra familiar, com a participação dos filhos, esposa e agregados familiares. Nos distintos ambientes de terra, floresta e água, as famílias desenvolvem suas práticas de agricultura (roça), cultivos de quintais e o extrativismo vegetal (plantas medicinais) e animal (pesca) (Fraxe, 2011).

$\mathrm{Na}$ Amazônia, recentemente, outras formas de coprodução têm surgido como experiências relevantes, na perspectiva do melhor uso, manejo e gestão dos recursos naturais, traduzindo o interesse dos agricultores à busca da sustentabilidade dos agroecossistemas de ilhas, várzeas e terra firme. Um exemplo são os sistemas agroflorestais (SAF), observados e estudados com frequência na região do município de Tomé-Açu. Melo Júnior, Kato e Façanha (2016), ao analisarem sistemas nesse contexto, os compreenderam como instrumentos de conservação dos recursos naturais na Amazônia Paraense. Outro exemplo são as experiências com o Manejo Florestal Comunitário e Familiar (MFCF), que tem conquistado espaço como alternativa econômica importante para comunidades rurais da Amazônia (Miranda et. al., 2018).

Segundo Silva, Tavares e Copetti (2018), nas áreas rurais do Território Baixo Tocantins, o sistema produtivo é baseado no extrativismo do açaí, pesca e no desmatamento para a retirada da madeira e implantação de roças de mandioca, arroz, milho e feijão. Ainda que o Território se apresente como lócus de importante produção agrícola, assim como em outras regiões do Pará, no Baixo Tocantins, os agricultores familiares encontram inúmeras lacunas na eficiência alocativa do crédito de fomento, dificultando a utilização dos recursos naturais para a obtenção de patamares mais elevados de desenvolvimento, por meio das políticas públicas de viés produtivo, a exemplo do 
Programa Nacional de Fortalecimento da Agricultura Familiar (Pronaf) ${ }^{6}$ (Fróes Júnior et al., 2019). Além do Pronaf, no Baixo Tocantins, há outras políticas públicas importantes como as de reforma agrária, de preservação ambiental, de desenvolvimento territorial ${ }^{7}$, especialmente, o Programa Nacional de Desenvolvimento Sustentável de Territórios Rurais (Pronat) ${ }^{8}$ e o Programa Territórios da Cidadania (PTC) ${ }^{9}$; e as políticas regionais.

E ainda segundo Silva, Tavares e Copetti (2018), neste espaço, observa-se uma complexa situação territorial com modelos de desenvolvimento, de sistemas e padrões diversos. Como exemplos destes padrões de desenvolvimento, Magalhães et al. (2012) citam as transformações ambientais decorrentes das mudanças na vazão do Rio Tocantins; do interesse puramente economicista de indústrias madeireiras; da implantação de um polo de biocombustível; e do complexo industrial mineral.

Estas transformações ambientais no Território do Baixo Tocantins se intensificaram durante a ditadura militar (1964-1985), no qual as indústrias madeireiras se multiplicaram pelo território, frente à imensa diversidade e oferta de matéria-prima que o mesmo possui. Já na década de 1970, a construção da Usina Hidrelétrica de Tucuruí impactou de forma incisiva na vazão do Rio Tocantins. $\mathrm{Na}$ década seguinte, surgiu o projeto do complexo industrial Albrás Alunorte, no município de Barcarena, que abriga diversas multinacionais que realizam produção de alumínio a partir da Bauxita. Mais recentemente, nos anos 2000, através de incentivos federais, houve a expansão dos cultivos de dendê para produção de biocombustível, especialmente nos munícipios de Tailândia e Moju, entretanto, este monocultivo já se faz presente em quase todos os munícipios do Baixo Tocantins.

Nos 11 municípios que compõem o Baixo Tocantins, a diversidade social das áreas rurais, segundo os dados disponíveis do Sistema de Informações Territoriais do Ministério do Desenvolvimento Agrário (SIT/MDA, 20--), é composta por agricultores familiares, famílias assentadas da reforma agrária, terras indígenas e comunidades quilombolas. Sobre os grupos étnicos citados, utiliza-se da contribuição de Lima (2020), ao reiterar que as práticas agrícolas destes, é observada através do conhecimento repassado oralmente a todos os seus descendentes. Estes saberes repassados de forma oral e por gerações constroem o conhecimento tradicional, característico das comunidades amazônicas (Diegues, 2000).

Especificamente acerca dos quilombolas, há um quantitativo de 189 comunidades no Território do Baixo Tocantins (Gomes, 2015), dentre estas, destaca-se a de Porto Alegre, em Cametá, lócus

\footnotetext{
6 Pronaf é um programa do Governo Federal criado em 1995, com o intuito de atender e subsidiar, por meio de financiamentos, os (as) agricultores familiares a desenvolverem suas atividades agrícolas.

7 Essas políticas foram implementadas entre 2003 e 2016, não tendo continuidade no governo de Michel Temer (20162018).

${ }^{8}$ O Pronat foi instituído pelo governo de Luiz Inácio Lula da Silva, no ano de 2003, com o intuito de dotar os Territórios Rurais admitidos pela Secretaria de Desenvolvimento Territorial (SDT) de melhores infraestruturas e serviços.

9 Consistiu-se em um Programa de enfrentamento da pobreza baseado na promoção do desenvolvimento econômico, ancorado na geração de trabalho e de renda e na universalização dos programas básicos de cidadania.
} 
desta pesquisa. Porto Alegre dialoga intrinsecamente com as características de agricultura apresentadas acima. A citar, especialmente, a importância do conhecimento produzido e transmitido oralmente pelos moradores da comunidade, o qual contribui para validar suas práticas socioeconômicas e culturais.

Em relação às atividades agrícolas, na comunidade de Porto Alegre, ações como a abertura de áreas, o plantio e as colheitas dos primeiros produtos da roça e até a construção de casas de farinha, locais nos quais é elaborada a farinha de mandioca, são realizadas por meio da prática do "convidado", cuja estrutura central está na iniciativa local de ação coletiva e nas interrelações entre os comunitários. Destaca-se que nessa espécie de mutirão quilombola há almoço, janta, chocolate com tapioca ${ }^{10}$, brincadeiras com as músicas de samba cacete ${ }^{11}$, cachaça, além do ritmo e da animação dos trabalhadores. Sobre o "convidado" praticado na comunidade de Porto Alegre, Siqueira (2019) o conceitua como:

Uma forma de trabalho coletivo, na qual, como a própria denominação sugere, alguns comunitários são convidados a realizar trabalhos de forma voluntaria, recebendo em troca apenas refeições e, em alguns casos, bebida alcoólica. Esta atividade contribui para manutenção da produção agrícola e, na maioria das vezes, acaba por se tornar um evento de diversão e entretenimento na comunidade (Siqueira, 2019, p. 14).

Por meio das inserções em campo, foi possível observar que na prática do "convidado", assim como nas atividades agrícolas na comunidade de Porto Alegre, a figura da mulher rural é essencial, apesar de não ocorrer seu devido reconhecimento. Dentre as diversas atividades desenvolvidas pelas mulheres da comunidade, destaca-se seu protagonismo na manutenção e gerenciamento dos quintais agroflorestais. Os quintais produtivos são administrados, em sua maioria, por mulheres, e são compreendidos como um agroecossistema, um espaço de produção agroecológica no entorno da casa, composto por um cultivo diversificado (pomares, hortas, plantas medicinais, água, pequenos animais) (Abrantes et al., 2013). Segundo os mesmos autores, também contribuem na construção de um desenvolvimento rural sustentável, orientado para atuar nas dimensões ambiental, social, econômica, cultural, política e de inclusão de gênero e geração.

Na comunidade de Porto Alegre, as mulheres quilombolas, apesar de toda carga de trabalho árduo, ainda são vistas como uma figura secundária no espaço laboral agrícola. Até mesmo as mulheres definem seu trabalho no plantio de mandioca e/ou nos quintais agroflorestais como "simples ajuda ao marido". Corroboram tal realidade os apontamentos de Quaresma (2015), que reitera que as

\footnotetext{
10 Alimento de origem indígena e feito a partir da fécula extraída da mandioca, que, ao ser espalhada em uma chapa aquecida, junta-se e vira um tipo de panqueca.

11 Manifestação cultural das comunidades quilombolas do Baixo Tocantins. Trata-se de um ritmo cadenciado por batuques de dois pedaços de pau (cacetes), acompanhado de cantos e de dança afro-brasileira e que, segundo Pinto, Costa e Domingues (2020), no passado era praticado por comunidades negras após um exaustivo dia de trabalho, por meio da reunião de distintos tambores, para a contemplação de um momento de descontração e alegria entre os seus.
} 
mulheres não se reconhecem nem são reconhecidas como trabalhadoras, por conta da invisibilidade de seu trabalho nas atividades produtivas, sempre considerado como uma "ajuda" ao trabalho do homem na roça.

Dessa forma, é factível afirmar que o esforço pela afirmação de identidade e de reconhecimento social representa para o conjunto de mulheres negras de Porto Alegre, destituídas de capital social, uma luta histórica que possibilita que as ações dessas mulheres no passado e no presente possam ecoar de tal forma a ultrapassar as barreiras da exclusão (Carneiro, 2003).

\section{A CONTRIBUIÇÃO DA APOSENTADORIA PARA A CONSTRUÇÃO DE AUTONOMIA DAS MULHERES QUILOMBOLAS}

Tendo em vista a proposta de análise do impacto que a aposentadoria rural possui para a autonomia das mulheres e, por conseguinte, à construção de novas capabilities, deve-se levar em consideração os contextos particulares no qual as entrevistadas estão inseridas. Nesse caso, as entrevistadas em questão são mulheres que vivem na área rural de um município do interior do estado, as quais são alijadas de modo mais pronunciado de políticas públicas específicas, levando em consideração suas condições de gênero, de classe e de raça/ cor/etnia. A condição de receptora da aposentadoria pode vir a constituir um canal de conexão entre essas mulheres e o Estado, entendido aqui como peça fundamental para o reconhecimento e ampliação da autonomia das mulheres.

As quatro mulheres entrevistadas da comunidade de Porto Alegre, com idades de 56, 69, 69 e 94 anos, dispõem de pouca escolaridade ou não foram alfabetizadas. Isso se deve ao fato de que na infância não havia escola perto do local onde residiam; faltavam condições materiais para poderem frequentar a escola, como material escolar, roupas e transporte; e havia a necessidade de trabalhar na produção de alimentos e tarefas domésticas. Essas mesmas condições que implicaram a falta de acesso à educação de mulheres integrantes de povos tradicionais (caboclos e indígenas) foram verificadas por Tecchio (2017) no Oeste de Santa Catarina.

A revelação de que já passaram fome e muitas dificuldades, como falta de acesso à moradia digna e alimentação é unânime nas falas das mulheres. Ao compararem sua situação presente com aquela vivenciada no passado, indicam estarem satisfeitas com as condições de vida que possuem, proporcionadas, em grande parte, pela aposentadoria, como revela o trecho de entrevista a seguir:

Eu, com 55 anos, me aposentei, graças a Deus. E aí, a vida mudou. Pra o que eu já passei, a vida está ótima, eu não tinha nem casa pra morar, eu tinha um tapiri ${ }^{12}$ malmente que era coberto com palha de inajá ${ }^{13}$ (Entrevistada 1. Agricultora quilombola, 69 anos, Cametá/PA, jan./2020).

\footnotetext{
12 Estrutura rústica, sem divisórias e semelhante a uma cabana, feita com materiais encontrados na floresta.

13 Palmeira abundante na Amazônia, que possui folhas alongadas, comumente utilizadas para cobertura de casas e locais de criação de animais.
} 
Segundo Costa (1984), a comparação da atual situação com a de um período anterior, no qual as condições de vida eram mais precárias, é uma das características subjetivas da pobreza. Mesmo aposentadas, quase todas as mulheres entrevistadas continuam a trabalhar em atividades agropecuárias, entre essas estão o preparo de área, o cultivo, a colheita e a criação de pequenos animais. Tonezer e Lopes (2009) ressaltam que, quando os idosos rurais se aposentam, a produção agrícola ganha um novo significado, ou seja, se antes eram "obrigados" a trabalhar para sobreviver, depois, continuam trabalhando pelo simples gosto de realizar as atividades. Na comunidade de Porto Alegre, as agricultoras aposentadas param de trabalhar na roça somente quando a condição física não as permite prosseguir, como revelam os trechos de entrevista abaixo:

Só quando eu estou doente que eu não vou para roça, mas a minha vida... hoje mesmo, já fui encoivarar ${ }^{14}$, fomos botar coivara. Já viemos de lá, já trouxemos meia carrada de mandioca com a minha neta, chegamos aqui, já beneficiamos tudinho. Já ralei tudinho, já tá tudo ralado na tábua e é assim a minha vida, sempre ativa no trabalho (Entrevistada 2. Agricultora quilombola, 69 anos, Cametá/PA, jan./2020).

Com a graça de Deus, esses tempos nós ainda tem a força pra tá trabalhando na roça. Com a graça de Deus, eu capino a roça, nós planta a maniva, eu capino a roça e agora, nesses tempos, eu planto milho, eu planto arroz e agora nós temos arroz, temos milho, temos maxixe, tudo eu tenho (Entrevistada 3. Agricultora quilombola, 94 anos, Cametá/PA, fev./2020).

Para as mulheres quilombolas da comunidade de Porto Alegre, a continuidade do trabalho no roçado e nos quintais, mesmo após a aposentadoria, é uma condição preponderante para o favorecimento e a manutenção de suas identidades construídas. Para elas, não encerrar a rotina de acordar cedo e caminhar bastante para o roçado, é algo que ultrapassa os fins econômicos, pois é uma atividade que lhes confere identidade. A mesma constatação é destacada por Ramos (2001), ao mencionar que a história de cada pessoa é registrada no corpo, e não é à toa que a ausência do trabalho deixa uma lacuna na vida dos idosos rurais.

As atividades produtivas das idosas nos roçados possuem uma nova dinâmica quando comparada à época em que não eram aposentadas, pois, atualmente, utilizam o dinheiro da aposentadoria para subsidiar inovações e novas relações de trabalho. Entre as principais inovações, segundo as entrevistadas, está à diversificação das roças. A renda advinda da aposentadoria, possibilita que as mulheres diminuam a dependência dos proventos da roça, ofertando às mesmas mais liberdade para modificarem a estrutura dos espaços de produção, com a introdução de novas espécies. Nas roças nas quais prevalecia o monocultivo de mandioca, agora são encontrados cultivos de melancia, arroz, milho e maxixe. Para além da diversificação da produção, a renda mensal garante a oportunidade de pagar diárias para que trabalhadores possam realizar atividades quando as

\footnotetext{
14 Prática agrícola tradicional, que ocorre após o processo de queima da capoeira ou da floresta primária, no qual se amontoam os troncos e pedaços de pau que não desagregaram para um novo processo de queima, a fim de deixar a área totalmente limpa e adubar o solo com as cinzas.
} 
aposentadas julgarem ser necessário, gerando renda para demais moradores da comunidade de Porto Alegre, como ressaltado nos trechos de entrevista a seguir:

Eu utilizo também [a aposentadoria rural] pra pagar trabalhador pra minha roça. Olha, agora mesmo, essa semana passada, eu paguei quatro diárias de 50 reais a diária pra irem coivarar, daí pago pra roçar pago pra ajudar a roçar então é uma ajuda que eu tenho pra mim custear o meu trabalho (Entrevistada 2. Agricultora quilombola, 69 anos, Cametá/PA, jan./2020).

A gente vai, olha, recebe esse dinheiro, traz arruma o trabalhador e ele trabalha com a gente e a gente tem de pagar eles, tem de pagar tudo, ele ajuda muito porque ele ajuda a dar força pra gente trabalhar pra gente fazer um serviço maior na roça. [...] [A aposentadoria] Ajuda mais na questão de pagar o trabalhador (Entrevistada 3. Agricultora quilombola, 94 anos, Cametá/PA, fev./2020).

Delgado e Cardoso Jr. (1999) destacam que a renda proveniente da aposentadoria rural possibilita às famílias formar um excedente monetário para reinvestir na atividade produtiva, tendo em vista que a aposentadoria representa um "seguro agrícola" ou mesmo um capital de giro nas propriedades familiares. É, assim, uma forma estratégica de sobrevivência e de reprodução social das famílias rurais, oferecendo aos aposentados maior segurança social, tornando-os menos dependentes dos ciclos agrícolas e da renda dos filhos.

As mulheres quilombolas relatam que estruturar seus espaços produtivos com os recursos financeiros obtidos por meio da aposentadoria rural é uma importante estratégia para que os filhos assumam a produção de alimentos da propriedade assim que elas não possuírem mais condições de trabalhar. As entrevistadas citam que essa "estruturação" seria principalmente materializada na continuação das atividades agrícolas nos roçados e na diversificação da produção, como evidencia o seguinte trecho de entrevista:

Eu estou pensando em, conforme for estes próximos anos que virão, eu vou entregar minhas ajudas [produção do roçado] já pros meus filhos que tá aí que eu não dou conta mais de trabalhar. Já vivo só doente, sinto muita dificuldade, então é isso. Não estou dando conta mais de trabalhar (Entrevistada 1. Agricultora quilombola, 69 anos, Cametá/PA, jan./2020).

Segundo Cazella et al. (2020) e Alcântara (2016), os recursos financeiros obtidos por meio da previdência rural, além de garantir necessidades básicas para as pessoas aposentadas, são compartilhados com os filhos. Este fato ocorre também entre os quilombolas da comunidade de Porto Alegre, sendo que as mulheres aposentadas fornecem, mensalmente, alimentos preparados ou não aos seus filhos que habitam no meio rural e urbano, como pode ser observado nestes trechos de entrevista:

Como eu faço aqui, que fim do mês eu já saio, quando eu chego em Cametá, eu pago meu patrão e faço nova compra, né? Minha despesa avortada aqui pra casa, pra não tá sem comer, porque a minha família é grande. Tem aqui e eu ajudo lá na cidade também os meus netos que moram lá, então, eu tenho que fazer duas despesas (Entrevistada 2. Agricultora quilombola, 69 anos, Cametá/PA, jan./2020).

Eu recebo seiscentos e uma fração porque eu tenho dois empréstimos. É, mas pra mim dá, graças a Deus. E a roça eu ajudo os meus filhos, aí a gente faz a farinha e eles vendem e eles 
ficam com essa renda, né? (Entrevistada 1. Agricultora quilombola, 69 anos, Cametá/PA, jan./2020).

Além de apoiar os filhos com recursos financeiros para a compra de alimentos, o dinheiro proveniente da aposentadoria permite às mulheres quilombolas oferecer um futuro melhor aos seus filhos, especialmente na questão educacional. Elas conseguem custear as despesas para que os filhos cursem o ensino médio na cidade de Cametá, uma vez que na comunidade apenas o ensino fundamental é ofertado.

Constatou-se que, no decorrer da vida das mulheres entrevistadas, o Estado teve presença limitada, de maneira que, além de pouca educação escolar, essas mulheres não tiveram nenhuma possibilidade de entrada no mercado de trabalho formal ou de obter renda por meio da produção agropecuária. Para Pontes e Steward (2019), a ausência de acesso aos direitos básicos, bem como a instabilidade jurídica com relação ao direito ao próprio território, demonstra como o racismo institucional limita a sobrevivência digna de mulheres e homens quilombolas. "Este fato resulta em tornar milhares de mulheres e homens invisíveis às políticas públicas específicas" (Pontes; Steward, 2019, p. 188).

Após o recebimento dos recursos financeiros, as mulheres passaram a escolher entre um ou outro produto, seja para alimentação ou vestuário dos filhos, a ir para a cidade comprar o que acharem importante em dado momento do mês, ou simplesmente planejar um futuro melhor para si e para os seus. Corroborando isto, abaixo segue o trecho de uma entrevista:

\footnotetext{
Se eu te falar, olha eu vou te dizer... Pra mim essa importância desse benefício foi uma coisa, pra mim, muito gratificável, muito bom, que me tirou de tudo as coisas ruim, porque vamos dizer... todo mês, eu vou, recebo o meu dinheiro e dá pra mim comprar a minha alimentação, dá pra eu comprar o meu remédio e dá pra tudo, graças a Deus, e por isso me acho feliz (Entrevistada 1. Agricultora quilombola, 69 anos, Cametá/PA, jan./2020).
}

A aposentadoria rural configura-se como uma das primeiras experiências de renda fixa destas mulheres, aumentando as suas capabilities, ao lhes ofertar o protagonismo na tomada de decisão sobre sua vida, sendo essa um fator significante para a autonomia das mulheres, especialmente em uma sociedade de estrutura patriarcal, como é a brasileira (Sardenberg, 2009). Nos casos em análise, essa tomada de decisão é ilustrada, conforme mencionado anteriormente, pela melhora nas condições de vida da família, diversificação dos cultivos, geração de renda para membros da comunidade, além de aprendizado em relação ao uso do dinheiro e maior liberdade que outrora para tomarem decisões referentes às suas vidas.

Como dito, a entrada da aposentadoria na vida dessas mulheres ampliou o seu espectro de escolhas. Nesse sentido, Rego e Pinzani (2013) citam que praticar o exercício do direito de escolha, como a compra de um tipo de alimento em relação a outro, ou de uma roupa, agregado à possibilidade 
de desenvolvimento de alguma de programação de vida, pode ser a via de passagem à esfera de maior liberdade pessoal para as mulheres. Essas "simples" ações são situações muito diferentes daquelas nas quais as mulheres encontravam-se excluídas. "Seu destino, do nascimento à morte, estava gravado profundamente nas suas subjetividades: seriam pobres, casadas muito jovens com homens também pobres, morariam em casebres e sequer escolheriam o número de filhos que gostariam de ter” (Rego; Pinzani, 2013, p. 37).

Os relatos apresentados e discutidos até aqui apontam que atualmente as entrevistadas, a partir dos proventos da aposentadoria, praticam o direito de escolha sobre os mais diversos espaços que permeiam seu cotidiano, além de demonstrarem um aumento na sua autoestima pessoal, frente ao período anterior, sem a renda regular. Em seu trabalho com mulheres beneficiárias do Programa Bolsa Família, Rego e Pinzani (2014) falam da relação entre dinheiro e autonomia. Assim como o Bolsa Família é, para muitas mulheres, seu único rendimento, como aponta Rego e Pinzani (2014), nos casos em estudo aqui, a aposentadoria rural também configura para as entrevistadas o único rendimento monetário regular. Para os autores citados, a renda em forma de dinheiro é uma condição real de início de processo de libertação de relações privadas opressoras e de controles sociais de sua intimidade. Ainda segundo esses autores, a escolha pessoal da vida que se quer viver é a base para pensar em autonomia e nas mulheres, e, nesse contexto de pobreza, não haveria essa perspectiva.

Além das significativas mudanças na vida das mulheres quilombolas citadas acima, a aposentadoria rural inicia a superação da cultura da resignação, que, segundo Sen (1985), é a espera da morte por fome e por doenças ligadas a ela. Segundo o mesmo autor, os desejos dos sujeitos estão de acordo com a realidade que estes vivenciam, logo, os pobres são despossuídos de esperança e desejam meramente sobreviver, e concentram seus esforços em assegurar sua próxima refeição. "Suas carências são emudecidas e silenciadas na métrica interpessoal da satisfação dos desejos”' (Sen, 1985, p. 191).

As quatro mulheres entrevistadas citam que a renda mensal lhes possibilitou oferecer um futuro melhor aos seus filhos e com mais oportunidades que tiveram, especialmente na questão educacional. Foi comum as interlocutoras citarem que seus filhos estão na cidade realizando o ensino médio ou formados e trabalhando, neste último caso, dividem-se entre os que conseguiram emprego na cidade e os que conseguiram emprego junto à comunidade: "Eu acho bom [a aposentadoria] porque, com a graça de Deus, foi o que me deu força pra mandar ensinar tudo os meus filho.[...] Eu ia recebendo e dava uma ponta pra eles... Agora, com a graça de Deus, todos eles têm a sua casa, sua família" (Entrevistada 3. Agricultora quilombola, 94 anos, Cametá/PA, fev./2020).

Como discutido no decorrer desta pesquisa, o acesso à renda mensal proporcionada pela aposentadoria rural acarretou inúmeras mudanças nas dinâmicas do cotidiano das mulheres de Porto Alegre, refletindo também em transformação na comunidade. Isto pode ser exemplificado pelo fato 
de as entrevistadas possuírem condições de subsidiar as suas necessidades básicas, assim como de seus filhos e filhas, além de garantir condições para que estes estudem e tenham mais possibilidade de ter emprego e renda. Sobre o aumento na liberdade do espectro de escolhas das mulheres, conseguido após acessarem a aposentadoria rural, reitera-se aqui o reflexo deste nas mudanças ocorridas tanto na configuração de suas roças, com o aumento da diversidade de espécies, como pelo fato de ofertar trabalho e consequentemente renda a terceiros, a partir dos seus espaços produtivos.

Assim sendo, pelos resultados encontrados, pode-se inferir que a aposentadoria representa uma conquista decisiva para o segmento social rural num contexto de ausências e de privação de acesso a outras políticas públicas, já que, pela primeira vez em sua trajetória, as mulheres da Comunidade de Porto Alegre passaram a dispor de uma garantia mínima de estabilidade no ambiente de incertezas em que sempre viveram, o que vai impactar diretamente nas suas condições de reprodução econômica e nas dos seus familiares. Para além, a política pública em estudo, também proporciona modificações nas roças, garantindo a introdução de inovações na agricultura quilombola que retroalimenta um desenvolvimento agrícola pautado no respeito ambiental e avanço social.

\section{CONSIDERAÇÕES FINAIS}

A invisibilização de certas comunidades rurais perante o Estado, em especial das quilombolas, adicionada à secundarização da imagem da mulher quilombola, arraigada por tempos no cotidiano de distintos territórios amazônicos brasileiros, reverberam e deixam marcas visíveis, observadas aqui na história de vida das participantes desta pesquisa. São mulheres que, em sua maioria, tiveram negado o direito ao acesso à educação, trabalho, renda e autonomia da própria vida. E que, somente após décadas, puderam disfrutar do mínimo de dignidade por meio do acesso a políticas públicas, neste caso em específico, da aposentadoria.

Reitera-se a importância de se possuir acesso facilitado aos números compilados sobre a aposentadoria (e também outras políticas públicas) nas comunidades quilombolas, tanto para embasamento de trabalhos científicos quanto para as mais diversas instâncias de projetos de desenvolvimento que venham a surgir tendo estes territórios como lócus de ação.

Ao verificar a importância da renda da aposentadoria rural para essas mulheres, deparou-se com múltiplas operacionalizações deste provento em suas vidas. A previdência rural se coloca como um importante veículo para a vida das idosas da comunidade de Porto Alegre, por subsidiar além das suas necessidades básicas, como alimentação para si e para seus dependentes, suas medicações e também o trabalho na roça. Apesar de aposentadas, as entrevistadas continuam a realizar trabalhos no campo, entretanto, sem mais a obrigação de outrora. E revelam que o provento da previdência rural se operacionaliza para o pagamento de pessoas nos trabalhos mais duros do roçado, e para a 
garantia de inovações que permeiam seu cotidiano agrícola. Muito além das necessidades básicas, a renda da aposentadoria rural no contexto da Comunidade de Porto Alegre proporciona a diversificação e manutenção dos cultivos na roça e nos quintais agroflorestais. Esta manutenção é geradora de apoio para que os filhos das aposentadas mantenham-se trabalhando nos espaços produtivos, e além dos proventos garantem novas relações de trabalho nas roças, pela contratação de pessoas do território para as atividades agrícolas.

A renda fixa, através da aposentadoria, é geradora do aumento das suas liberdades (capabilities), refletida num importante grau de autonomização da sua vida, que lhes garante liberdade de escolhas de alimentação, mais autonomia monetária, confiança dos comerciantes e diminuição de sentimentos de vergonha, além da garantia de suas necessidades mais básicas, levandoas a considerar que estão superando a pobreza extrema e, enfim, alcançando sua autonomia.

\section{REFERÊNCIAS}

ABRANTES, K. K. et al. Os Meios de Comercialização do Excedente do Quintal Produtivo: Desenvolvendo uma Ação Humana Sustentável. In: ENCONTRO REGIONAL DA SOBER NORDESTE, 8, 2013, Parnaíba. Anais do VIII SOBER Nordeste. Parnaíba: Sober, 2013.

ALCÂNTARA, A. ENVELHECER NO CONTEXTO RURAL: A VIDA DEPOIS DO APOSENTO. In: ALCÂNTARA, A; CAMARANO, A. A.; GIACOMIN, K. C. (Orgs). Política Nacional do idoso: velhas e novas questões. Rio de Janeiro: Instituto de Pesquisa Econômica Aplicada (Ipea), 2016, p. 323-342.

BARDIN, L. Análise de conteúdo. Lisboa: Edições 70, 1979.

BRASIL. Lei no 8.213/1991 de 24 de julho de 1991. Dispõe sobre os Planos de Benefícios da Previdência Social e dá outras providências. Diário Oficial da União, Brasília, DF, 14 ago. 1991. Disponível em: < http://www.planalto.gov.br/ccivil_03/leis/18213compilado.htm>. Acesso em: 24 abr. 2020.

CARNEIRO, S. Mulheres em movimento. Estudos avançados, v. 17, n. 49, p. 117-133, 2003.

CAZELLA, A.A. et al. Sistemas agrícolas e alimentares de famílias rurais: análise da multilocalização familiar na região Oeste de Santa Catarina. Estudos Sociedade e Agricultura, n. 28, v. 1, p. 21-47, 2020.

COSTA, A. B. Conceito de pobreza. Estudos de Economia, v. 1, n. 3, p. 275-295, 1984.

DELGADO, G. C. Previdência social e desenvolvimento rural. In: Catia Grisa [e] Sergio Schneider (Org.). Políticas públicas de desenvolvimento rural no Brasil. Porto Alegre: Editora da UFRGS, 2015, p. 429-442.

DELGADO. G. C.; CARDOSO JR., J. C. O idoso e a previdência rural no Brasil: a experiência recente da universalização. IPEA. Instituto de Pesquisa Econômica Aplicada. Rio de Janeiro, dezembro de 1999. Texto Para Discussão, p. 1-23.

DIEGUES, Antonio Carlos (org). Os Saberes Tradicionais e a Biodiversidade no Brasil. São Paulo: MMA, COBIO, NUPAUB, 2000.

FRAXE, T. de J. P. Comunidades Ribeirinhas Amazônicas: Memória, Ethos e Identidade. Manaus: Reggo edições, 2011. 
FRÓES JUNIOR, P. S. M. et al. Sources of Growth and Spatial Concentration of Coconut Crop in the State of Pará, Brazilian Amazon. Journal of Agricultural Science, v. 11, n. 2, p. 159-169, 2019.

FUCKS, P. M; FERREIRA, L. F. Memória do trabalho, cultura e território quilombola. In: Congresso Brasileiro de Sociologia, 2013, Salvador. Anais do XVI Congresso Brasileiro de Sociologia, Salvador: Sociedade Brasileira de Sociologia, 2013.

GOMES, Flávio dos Santos. Mocambos e quilombos: uma história do campesinato negro no Brasil. São Paulo: Editora Companhia das Letras, 2015.

INSTITUTO BRASILEIRO DE GEOGRAFIA E ESTATÍSTICA (IBGE). Censo 2010 - resultados preliminares. Disponível em: $<$ http://www.ibge.gov.br/home/estatistica/populacao/censo2010/tabelas_pdf/total_populacao_para. pdf $>$. Acesso em: 17 Jun. 2020.

INSTITUTO NACIONAL DE PREVIDÊNCIA SOCIAL (INSS). Boletim Estatístico da Previdência Social, Novembro/2019 - $\quad$ V $\quad 34 \quad N$. 11. 2019a. Disponível em: $<$ http://sa.previdencia.gov.br/site/2019/12/Beps1112019_trab_Final1_portal.pdf $>$. Acesso em: 03 Jun. 2020.

INSTITUTO NACIONAL DE PREVIDÊNCIA SOCIAL (INSS). POPULAÇÃO E BENEFÍCIOS PREVIDENCIÁRIOS NAS UNIDADES DA FEDERAÇÃO. 2019b. Disponível em: $<$ https://www.gov.br/previdencia/pt-br/acesso-a-informacao/dados-abertos/previdencia-socialregime-geral-inss/estatisticas-municipais-2019>. Acesso em: 06 Jun. 2020.

ITERPA. Quilombolas. 2020. Disponível em: <http://www.iterpa.pa.gov.br/content/quilombolas-0>. Acesso em: 26 Jul. 2020.

JORGE, A. L; BRANDÃO, A. A. P. Androcentrismo Institucional e Acesso a Aposentadoria Rural entre Mulheres Quilombolas da Comunidade de Agreste-MG. Revista Ártemis, v. 13, n. 1, p. 161$173,2012$.

LIMA, K. N.; FILHO, R. P. F. Agricultura familiar no contexto socioambiental Amazônico. Revista direitos sociais e políticas públicas (UNIFAFIBE), v. 8, n. 1, p. 283-306, 2020.

MAGALHÃES, S. B. et al. Transformações sociais e territoriais no ambiente rural da Amazônia Oriental. In: VI Encontro Nacional da ANPPAS, v. 8, 2012, Belém. ENCONTRO NACIONAL DA ANPPAS. Belém: 2012.

MELO JÚNIOR, J. G.; KATO, O. R.; FAÇANHA, T. P. Conservação dos recursos naturais na comunidade Santa Luzia, município de Tomé-Açu/Pará: uma experiência de produção com sustentabilidade na Amazônia através de sistemas agroflorestais. Cadernos de Agroecologia, v. 10, n. 3, 2016.

MIRANDA, K. et al. Mulheres e o planejamento do manejo florestal comunitário e familiar na Reserva Extrativista Verde para Sempre. Cadernos de Agroecologia, v. 13, n. 1, 2018.

PEDROSO JÚNIOR, N. N. et al. A casa e a roça: socioeconomia, demografia e agricultura em populações quilombolas do Vale do Ribeira, São Paulo, Brasil. Boletim do Museu Paraense Emílio Goeldi. Ciências Humanas, v. 3, n. 2, p. 227-252, 2008.

PONTES, M. C. C. L.; STEWARD, A. M. Invisibilidade da pluriatividade da mulher quilombola: o caso de Moju-Miri. Agricultura Familiar: Pesquisa, Formação e Desenvolvimento, v. 13, n. 2, 186207, 2020.

QUARESMA, A. P. Mulheres e quintais agroflorestais: a "ajuda invisível" aos olhos que garante a reprodução da agricultura familiar camponesa amazônica. In: HORA, K, MACEDO, G, REZENDE, M. (Orgs). COLETANNEA SOBRE ESTUDOS RURAIS E GENNERO. Brasília: Ministério do Desenvolvimento Agrário, 2015, p. 35-43. 
RAMOS, V. Corpo e movimento no envelhecimento: reflexões de idosos sobre as transformações do seu corpo. Revista Kairós, São Paulo, v. 4, p. 67-81, 2001.

REGO, W. L; PINZANI, A. Vozes do Bolsa Família: autonomia, dinheiro e cidadania. São Paulo: Editora Unesp, 2014.

REGO, W. L; PINZANI, A. Liberdade, dinheiro e autonomia. O caso da Bolsa Família. Política \& Trabalho, v. 1, n. 38, p. 21-42, 2013.

ROBEYNS, I. The capability approach. Stanford, California, 14 Apr. 2011. Encyclopedia of Philosophy. Disponível em: <https://plato.stanford.edu/entries/capability-approach/>. Acesso em: 19 Abr. 2020.

SARDENBERG, C. Conceituando "empoderamento" na perspectiva feminista. In: SEMINÁRIO INTERNACIONAL: TRILHAS DO EMPODERAMENTO DE MULHERES, n. 1, 2006, Salvador. SEMINÁRIO INTERNACIONAL: TRILHAS DO EMPODERAMENTO DE MULHERES. Bahia: UFBA, 2009.

SANTOS, I. M. M., SANTOS, R. S. A ETAPA DE ANÁLISE NO MÉTODO HISTÓRIA DE VIDA - UMA EXPERIÊNCIA DE PESQUISADORES DE ENFERMAGEM. Revista Texto Contexto Enferm, Florianópolis, v. 17, n. 4, p. 714-719, 2008.

SEN, A. A ideia de justiça. 1. ed. São Paulo: Companhia das Letras, 2011.

SEN, A. Desenvolvimento como liberdade. Trad. Laura Teixeira Motta. São Paulo: Companhia das Letras, 2000.

SEN, A. Well-being, Agency, and Freedom. Journal of Philosophy, New York, apr 1985. The Dewey Lectures 1984. p. 169-221.

SILVA, C. W., TAVARES, F. B., COPETTI, L. D. FEIRAS DE ECONOMIA SOLIDÁRIA E MERCADOS LOCAIS DA AGRICULTURA FAMILIAR NO BAIXO TOCANTINS (PARÁ). RTPS-REVISTA TRABALHO, POLÍTICA E SOCIEDADE, v. 3, n. 4, p. 235-264, 2018.

SIQUEIRA, Patrícia Benedita de Leão. Juventude rural e organização social: uma análise da associação de remanescentes de quilombo de Porto Alegre, Cametá/PA. Cametá, Pará, 2019. $48 \mathrm{f}$. Trabalho de Conclusão de Curso (Bacharel em Agronomia) - Faculdade de Agronomia, Universidade Federal do Pará, Cametá, 2019.

SISTEMA DE INFORMAÇÕES TERRITORIAIS / MINISTÉRIO DO DESENVOLVIMENTO AGRÁRIO - SIT / MDA. 20--. Disponível em: <http://sit.mda.gov.br/pesquisa.php> Acesso em: 26 out. 2020.

TECCHIO, Andréia. Pobreza e territorialização da ação pública no Território Meio Oeste Contestado (SC). Seropédica - RJ, 2017. 289 f. Tese de Doutorado (Doutorado em Ciências Sociais) - Universidade Federal Rural do Rio de Janeiro, 2017.

TONEZER, C.; LOPES, M. J. M. Efeitos da Cobertura Previdenciária na situação de vida de idosos rurais de Santana da Boa Vista - Rio Grande do Sul. INTERTHESIS, Florianópolis, v. 6, n. 2, p. 191209, 2009.

VALADARES, A. A.; GALIZA, M. Previdência rural: contextualizando o debate em torno do financiamento e das regras de acesso. Instituto de Pesquisa Econômica Aplicada (Ipea). Brasília, maio. 2016:. Nota Técnica, p. 65.

VINUTO, J. A amostragem em bola de neve na pesquisa qualitativa: um debate em aberto. Temáticas, v. 22, n. 44, p. 202-218, 2014.

WANDERLEY, M. N. Raízes históricas do campesinato brasileiro. In: TEDESCO, J. C. (Org.). Agricultura familiar: realidades e perspectivas. 3. ed. Passo Fundo: Editora da UPF, 2001. p. 21-55. 